\title{
A METHOD OF OBTAINING CULTURES FROM THE DUODENUM OF INFANTS. ${ }^{*} \dagger$
}

\author{
Alfred F. Hess.
}

(From the Research Laboratory, Deparlment of Health, New York City.)

Ever since Escherich ${ }^{x}$ published his classic monograph on the flora of the intestine during infancy, this field has been a favorite one for bacteriologists. They have, however, found themselves hampered not only by the difficulties attendant on growing intestinal bacteria, but by the difficulty of isolating pathogenic organisms from the multitude of saprophytic bacteria which flourish in the lower intestinal tract. Bearing this in mind, it seemed as if the duodenal catheter, devised primarily for the purpose of the diagnosis and treatment of pyloric stenosis, might be of value in this connection and afford a new method for the approach of this subject. This instrument is merely a soft rubber Nelaton catheter No. I4 or No. I $5(\mathrm{~F})$ and marked in an appropriate manner. It can be inserted through the pyloric sphincter and into the duodenum in infants, from the time of birth up to the age of two years, with a facility comparable to the passage of the ordinary stomach-tube in the adult. It seems hardly necessary to outline the technic of this procedure, in view of the fact that a previous article $^{2}$ describes it in detail, including radiographs which clearly demonstrate the presence of the catheter within the lumen of the upper intestine.

For the purpose of bacterial investigation this duodenal catheter was sterilized and then capped at the end with a gelatin capsule, such as the apothecary frequently makes use of in dispensing drugs. This capsule had been sterilized by dry heat at $160^{\circ} \mathrm{C}$. and then, by means of sterile forceps, was slipped over the eye at the end of the catheter, and fastened by slightly moistening with

* Received for publication May 7, I912.

f Presented at the Annual Meeting of the Association of American Bacteriologists and Pathologists, April 6, Ig12.

I Die Darmbakterien des Säuglings, 1886.

a Am. Jour. Dis. Children, I91 2, 3, p. I33. 
sterile water. The catheter thus prepared was passed in the usual way into the mouth and the stomach, and then introduced gently through the pylorus into the duodenum. In general the pylorus can be traversed by this means within three to five minutes. It was found that the capsule, which had become hardened, due to the heat of sterilization, did not melt before it reached the duodenum; this was readily ascertained by means of aspiration, for as soon as the end of the catheter is open, a drop or two of gelatin can be aspirated, whereas as long as it is closed, a marked sense of resistance to aspiration is encountered. By means of this technic it is possible to obtain the contents of the duodenum and of the jejunum, by the aid of antiperistalsis, with but very slight contamination from the mouth or the stomach. It is probable that a slight degree of contamination generally results, but, judged from what follows, this could not have occurred to a considerable degrec. As an additional safeguard, the gelatin covering the eye of the catheter, which might constitute a source of contamination, was not sucked up with the first aspiration, but, on the contrary, was blown off the end of the tube.

The first tests were made upon new-born babies, a few hours old, before they had taken any food whatsoever. This group consisted of four cases. Very few bacteria were found in the stomach and in the duodenum. Only one to three bacteria to a platinum loop of the fluid. These were staphylococci, molds, gram-positive and, less often, gram-negative bacilli. No colon bacilli were found.

Next, I I babies were tested during the first week of life. In each case a test of the stomach contents was first made, then one of the duodenal contents, the tests being carried out when the stomach was comparatively empty. Here, again, very few bacteria were found in the duodenum, and the same varieties were cultivated as in the new-born babies. As was to be anticipated, there was a general concordance between the bacteria of the stomach and those found in the upper intestine. In only one case of this series was the colon bacillus, or, indeed, any gas-producing organism, obtained; in these tests $0.3^{-0.5}$ c.c. of intestinal contents was cultivated. For comparison, a test of the mecomium was 
made for the presence of the colon bacillus. The earliest that this organism was met with was in the case of an infant $\mathrm{I} 2$ hours old. Generally it was not found in the mecomium. In this connection we may call attention to the work of Escherich, of Moro, and of Herter, who found the colon bacillus quite frequently in the mecomium, and therefore suggested that this bacillus first gains access to the gastro-intestinal tract by way of the rectum. The most common bacterium in the upper intestine during this period of life was the staphylococcus, in the stomach as well as in the duodenum. The bacteria seemed to be almost entirely of the facultative variety, for anaerobic cultures failed to show other organisms than those grown under aerobic conditions. It was found that the presence or absence of free hydrochloric acid in the stomach, or of a small or large quantity of bile in the intestine, did not play a constant rôle as regards the number of bacteria obtained. In tests made upon somewhat older infants, two to six weeks of age, the colon bacillus was almost regularly cultivated from the duodenum, and with a less degree of constancy from the stomach. However, these various tests are not considered conclusive and are given, not so much with the idea of furnishing a definite qualitative and quantitative test of the normal flora at this period of life, for we realize that they are insufficient in number to serve this purpose, but rather to show how this method may be made use of in this connection. The number of bacteria cultivated from the stomach was found almost always to be in excess of that met with in the duodenum, which, in itself, furnishes a conclusive argument that the duodenal cultures were not merely contaminations from the mouth and the stomach. The number of bacteria in the duodenal contents was at no time great. During the first few days of life hardly more were found than in the tests made before the infant had ever nursed. At this period and a little later, 25 to Ioo bacteria were usually grown from a loop of intestinal contents, and even in infants several weeks of age not more than 100 to 200 organisms were cultivated per platinum loop. In the case of bottle-fed babies the number of bacteria was regularly higher. This comparative sterility of the duodenum was not surprising in view of the work of Kohlbrugge and others on the 
auto-sterilization of the intestines. Some years ago bacteriological tests of the contents of the intestine of rabbits, which we undertook in connection with a study of antiperistalsis, also demonstrated this fact decisively.

In addition to these general considerations, we should like to mention two specific instances where these tests seemed to be of clinical interest. One was the case of an infant a week old, who had gastro-intestinal symptoms, coated tongue, some vomiting, and green stools; in this instance repeated tests showed a large number of staphylococci in the stomach, and a still larger number in the duodenum.

The opportunity presented itself of passing the catheter upon a baby 22 months old, suffering from typhoid fever in the beginning of the third week, and giving a positive Widal reaction. A small amount of bile-containing fluid was aspirated from the duodenum, and from this fluid typhoid bacilli were cultivated in very large numbers. The marked success in this instance strengthened the idea that this simple procedure might be of value in this connection in the diagnosis of typhoid carriers. Although this catheter cannot be used upon adults, as it does not readily pass through the pylorus where the stomach is large and the sphincter is resistant, a duodenal tube, as devised by Gross or by Einhorn, which in the course of a few hours is carried into the duodenum by means of peristalsis, might well be used for this purpose. This tube is very thin and causes very little inconvenience, as I have had opportunity to observe. The advantages of a duodenal test for typhoid bacilli, over a test of the stool, is considerable, as the duodenum is the estuary for typhoid bacilli. In the intestine by far the greatest number of typhoid bacilli are found in the duodenum and the jejunum, as could be presupposed when we consider that they are in the blood at the very onset of the disease, that they are partly excreted from the blood into the bile, and having multiplied in this fluid are poured into the upper intestinal tract. In this connection we should also remember that one of the very last organs of the body that they forsake is the gall bladder, which is the favorite nidus of this bacillus within the body of the typhoid carrier (Chiari). A clear and conclusive conception of the inci- 
dence of the typhoid bacillus in the gall bladder and the various levels of the intestinal tract may be obtained from the table of Gaehtgen ${ }^{\mathrm{r}}$ which is appended (Table $\mathrm{r}$ ). From this table, which gives the results of cultures taken post mortem in cases of typhoid and typhoid carriers, it is clear that the typhoid bacilli decrease in numbers in the intestinal tract as we proceed downward from the duodenal opening of the bile duct to the rectum, and that they are to be found most constantly in the gall bladder.

This idea of cultivating typhoid bacilli from the duodenal contents, rather than from the stool, is not entirely original. Some years ago Weber made an attempt of this kind on account of the difficulty which had been experienced by others in cultivating typhoid bacilli from the stools of carriers. Kayser, ${ }^{2}$ of the Kaiserliche Gesundheitsamt, found in a series of cases, that three repeated examinations at long intervals failed to show typhoid bacilli, where later tests proved the individuals to be carriers, and therefore recommended as a safeguard that tests of carriers should be carried out every two or three months for a period of a year. In view of the inadequacy of stool examinations, Weber ${ }^{3}$ made use of Volhard's oil breakfast, which consists in giving about 200 c.c. of olive oil by mouth to incite a regurgitation of the duodenal contents into the stomach. He then attempted to cultivate typhoid bacilli from the stomach contents. In three patients, two of whom were typhoid carriers and one a paratyphoid carrier, a very large number of typhoid colonies were thus obtained, whereas they were cultivated but sparsely from the stool. Wherever bile was found in the stomach, typhoid bacteria were likewise found in large numbers. The only difficulty was that the duodenal contents could not always be obtained by this means.

We wish in this paper merely to present for consideration a method for the diagnosis and the study of bacterial conditions of the intestine. It is possible that this technic may also be of value in connection with diseases of known, or unknown origin, associated with animal parasites, such as, for instance, amebic infection of the intestine or of the liver. It may also have an application

Berl. klin. Wchnschr. I912, 49, p. 296.

2 Arb. a. d. k. Gsndhtamte., - 1906, 24, p. 173 .

3 Munchen med. Wchnschr., 1908, 55, p. 2443. 
in the study of the influence of the various food-stuffs upon the bacterial flora of the intestine. However, in addition to its practical value in the diagnosis of the typhoid carrier, at present its main field of usefulness would seem to be in the study of dysentery and enteritis, diseases which play such an important rôle in the morbidity and mortality of early life, and which it is difficult to investigate satisfactorily by the aid of cultures from the stool on account of the vast number of contaminating bacteria. This difficulty is not encountered in cultures taken from the upper part of the intestinal tract.

\section{TABLE I.}

Post Mortem Cultures of Typhotd Cases and Carriers, Showing Incidence of B. Typhosus in Gall BLAdDER and Various Levels of the INTESTINe.

\begin{tabular}{|c|c|c|c|c|c|c|c|c|c|c|c|c|}
\hline & \multicolumn{2}{|c|}{$\begin{array}{c}\text { GALI } \\
\text { BLADDER }\end{array}$} & \multicolumn{2}{|c|}{ Duodenum } & \multicolumn{2}{|c|}{ JEJLNOM } & \multicolumn{2}{|c|}{ ILEUM } & \multicolumn{2}{|c|}{ COLON } & \multicolumn{2}{|c|}{ Rectum } \\
\hline & + & - & + & - & + & - & + & - & + & - & + & - \\
\hline $\begin{array}{l}\text { rst } \\
\text { 2deek. } \\
\text { 2d } \\
\text { 3d }\end{array}$ & $\begin{array}{l}\because \\
2 \\
6 \\
2 \\
2 \\
\because \\
2 \\
1\end{array}$ & $\begin{array}{l}\because \\
\mathbf{I} \\
\because \\
\because \\
\because \\
\because \\
\cdots\end{array}$ & $\begin{array}{l}2 \\
2 \\
2 \\
2 \\
\cdots \\
\cdots \\
\cdots\end{array}$ & $\begin{array}{l}\mathbf{I} \\
\because \\
2 \\
\mathbf{I} \\
\therefore \\
\because \\
\because \\
\therefore\end{array}$ & $\begin{array}{r}2 \\
2 \\
3 \\
\mathbf{I} \\
2 \\
\mathbf{1} \\
\mathbf{x}\end{array}$ & \begin{tabular}{r|r}
$\mathbf{I}$ \\
$\mathbf{2}$ \\
$\mathbf{2}$ \\
$\mathbf{2}$ \\
$\mathbf{I}$ \\
\hdashline \\
$\mathbf{I}$
\end{tabular} & $\begin{array}{l}\because \\
\mathbf{x} \\
2 \\
\mathbf{x} \\
\because \\
\because \\
\because \\
\cdots\end{array}$ & $\begin{array}{r}\mathbf{I} \\
\mathbf{2} \\
3 \\
3 \\
\mathbf{I} \\
2 \\
2\end{array}$ & $\begin{array}{l}\because \\
\mathbf{I} \\
I \\
\ddot{I} \\
\cdots \\
\because\end{array}$ & $\begin{array}{r}\dddot{1} \\
7 \\
2 \\
1 \\
\because \\
2 \\
1\end{array}$ & $\begin{array}{l}\because \\
\because \\
\because \\
\because \\
\cdots\end{array}$ & $\begin{array}{r}\mathbf{r} \\
\mathbf{2} \\
\because \\
4 \\
\because \\
\because \\
\cdots\end{array}$ \\
\hline Total.... & 15 & $\mathbf{I}$ & 6 & 4 & ro & 9 & 4 & I2 & 3 & 14 & $\circ$ & 7 \\
\hline Per cent. . . & 96 & & 60 & & 53 & & 27 & & I8 & & $\circ$ & \\
\hline
\end{tabular}

$+=$ Typhoid bac.

$-=$ No typhoid bac. 